\title{
PENTINGNYA PENGETAHUAN PERAWAT TENTANG DIAGNOSA KEPERAWATAN
}

\section{Maranti Syah}

\section{Email: marantisyah555@gmail.com}

\begin{abstract}
ABSTRAK
Latar Belakang: Diagnosa keperawatan merupakan penilaian klinis terhadap pengalaman atau respon individu, keluarga, dan komunitas pada masalah kesehatan pada masalah kesehatan atau pada proses kehidupan. Diagnosis keperawatan adalah bagian vital dalam menentukan asuhan keperawatan yang tepat untuk membantu klien memperoleh kesehatan yang optimal. Diagnosis keperawatan dibuat berlandaskan dari hasil pengkajian yang diterapkan oleh perawat sesuai dengan apa yang tertuang dalam format pengkajian. Dokumentasi keperawatan mempunyai peran penting dalam aspek hukum, kualitas pelayanan, komunikasi, pendidikan, penelitian, dan akreditasi. Metode: Metode yang digunakan ialah menggunakan literature review. Hasil: Perawat memiliki pengetahuan tentang diagnosa keperawatan dan perawat mampu merumuskan diagnosa keperawatan dengan benar dan tepat.
\end{abstract}

\section{Kata Kunci: Pengetahuan, Perawat, Diagnosa Keperawatan}

\section{LATAR BELAKANG}

Keperawatan merupakan bentuk pelayanan kesehatan professional yang berupa pemenuhan kebutuhan dasar yang diberikan kepada individu yang sehat maupun yang sakit, yang mengalami gangguan fisik, psikis, serta sosial agar dapat mencapai tujuan derajat kesehatan yang optimal. Bentuk dari pemenuhan dasar bisa seperti meningkatkan kemampuan yang ada pada individu, mencegah, memperbaiki, serta melakukan rehabilitasi dari suatu keadaan yang dipersepsikan sakit oleh individu.

Keperawatan ialah suatu bentuk pelayanan profesional bersifat humanistik, menggunakan pendekatan holistik, dilakukan berdasarkan dengan ilmu dan kiat keperawatan, berorientasi kepada kebutuhan objektif klien. Praktik keperawatan mengacu kepada standar profesional keperawatan dan menggunakan etika keperawatan sebagai acuan utama. Perawat dituntut untuk selalu 
melaksanakan asuhan keperawatan yang benar atau rasional (Nursalam, 2007).

Perawat sebagai seorang tenaga kesehatan yang bertugas untuk memenuhi kebutuhan dasar klien secara holistic memiliki tanggung jawab untuk dapat membantu pemenuhan kebutuhan oksigen klien yang tidak adekuat. Dalam tindakannya, seorang perawat sebelum memberikan asuhan keperawatan kepada pasien harus melakukan metode keperawatan berupa pengkajian, diagnosis keperawatan, intervensi, dan evaluasi. Proses asuhan keperawatan ialah tugas dan kewajiban seorang perawat dari pasien datang sampai pasien pulang, dimulai dari di lakukannya pengkajian secara menyeluruh, kemudian menegakkan diagnosa keperawatan dari data yang didapat dari pengkajian tersebut, serta melaksanakan intervensi, implementasi dan evaluasi keefektifan diagnosa awal yang sudah ditegakkan (Nursalam, 2007).

Profesi perawat mempergunakan proses keperawatan (nursing process) sebagai kerangka pikir dan kerangka kerja dalam merawat pasien. Keperawatan sebagai proses, dipublikasikan sejak tahun 1955 oleh Hall dan pada tahun 2004 proses keperawatan (nursing process) ditetapkan sebagai series of steps oleh ANA (American Nursing Association) (Wilkinson, 2007), yang terdiri atas assesment (pengkajian), diagnosis (penetapan diagnosis), planning outcomes (perencanaan hasil), planning intervention (perencanaan intervensi), implementation (implementasi) dan evaluation (evaluasi).

Pada tindakannya kegiatan proses keperawatan di atas tidaklah selalu berurutan tetapi dapat dikerjakan pada waktu bersamaan/tumpang tindih (overlapping). Salah satu kegiatan yang penting dalam proses keperawatan ialah pengkajian keperawatan. Pengkajian keperawatan ini sangat penting dikarenakan dari pengkajian keperawatan maka perawat dapat menentukan apa masalah keperawatan/diganosa keperawatan dan masalah kolaboratif/diagnosis potensial komplikasi yang dialami oleh pasien dan dapat membuat perencanaan dalam merawat pasien.

Diagnosis keperawatan adalah penilaian klinis terhadap pengalaman/respon individu, keluarga, atau komunitas pada masalah kesehatan/risiko masalah kesehatan atau pada proses kehidupan. Diagnosis keperawatan ialah bagian penting dalam menentukan asuhan keperawatan yang sesuai untuk membantu klien mencapai kesehatan yang optimal. Perawatan yang profesional diperlihatkan dalam pendokumentasian yang profesional, yang membuktikan tentang 
apa yang dilakukan oleh perawat dan secara efektif menggambarkan status dan kemajuan klien.

Pengalaman menyatakan bahwa sering sekali perawat kesulitan dalam menentukan diagnosis keperawatan spesifik yang dialami oleh pasien. Hal ini mungkin terjadi dikarenakan pengkajian keperawatan yang tidak terstruktur dengan baik. Pengalaman memperlihatkan bahwa pengkajian yang dilakukan oleh perawat tidak mempunyai urutan yang benar dan terkait dengan diagnosis keperawatan. Sering kali terjadi perawat mempunyai data tertentu tetapi kebingungan dalam menentukan data tersebut. Atau sebaliknya perawat memiliki prediksi dimana pasien memiliki diagnosis tertentu tetapi perawat tidak tahu data apa yang perlu dikaji untuk mendukung diagnosis tersebut muncul (Nurjannah, 2010).

Persatuan Perawat Nasional Indonesia (PPNI) adalah Organisasi Profesi (OP) yang diakui dalam UU Keperawatan yang memiliki tanggung jawab dalam meningkatkan dan mengembangkan pengetahuan dan keterampilan, martabat, dan etika profesi perawat di Indonesia. Dalam mencapai tujuan dan menjalankan dari fungsi tersebut, salah satunya PPNI berkewajiban untuk membuat standarstandar yang meliputi standar kompetensi, standar asuhan keperawatan, dan standar kinerja profesional. Standar asuhan keperawatan diperlukan Standar Diagnosis Keperawatan, oleh karena itu PPNI menerbitkan Standar Diagnosis Keperawatan Indonesia (SDKI).

\section{METODE}

Metode yang di gunakan dalam kajian ini yakni metode literature review, di mana pada kajian ini di buat berdasarkan berbagai suber bacaan yang seperti, buku bacaan, jurnal, tesis juga ataupun ebook yang berhubunga dengan diagnosa dalam keperawatan. Literatur review merupakan uraian tentang teori, temuan, serta bahan penelitian lain yang didapatkan dari bahan acuan untuk dijadikan sebagai landasan kegiatan penelitian untuk menyusun kerangka pemikiran yang jelas dari perumusan masalah yang ingin di teliti.

Kajian ini juga merupakan kajian bebas dimana adalam kajian ini bersifat bebas dimana kajian ini juga di buat dengan cara perbandingan melalui artikel satu dengan artikel artikel yang lainnya dan menghasilkan perbandingan yang di tulis secara berurutan dan bertauran dalam hasil kajian ini agar mendapatkan pembahasan sesuai dengan topik, penulisan kajian ini melibatkan banyak media cetak maupun media online yang membahas masalah sesuai dengan topik yang di kaji di jurnal ini. Referensi yang digunakan yakni jurnal 
dan artikel ilmiah pada penerbitan 8 tahun terakhir. Dalam mencari referensinya, menggunakan kata kunci diagnose ,asuhan,dan keperawatan.

\section{HASIL}

Perawat mempunyai pengetahuan terkait diagnose keperawatan. Pada literature review didapatkan hasil bahwa pengkajian keperawatan dan perumusan diagnosa keperawatan mengawali langkah awal dari perencanaan proses keperawatan. Perencanaan ialah kategori dari perilaku keperawatan dimana dengan tujuan yang berpusat pada klien dan hasil yang diperkirakan ditetapkan dan intervensi keperawatan dipilih agar mencapai tujuan tersebut.

Melalui identifikasi, bisa digambarkan berbagai masalah keperawatan yang membutuhkan asuhan keperawatan.Salah satu kompetensi perawat bisa merumuskan diagnosa keperawatan yang baik dan benar, dimana diagnosa keperawatan adalah kesimpulan yang dihasilkan dari analisis data, sehingga menghasilkan pernyataan yang jelas, singkat dan pasti tentang masalah pasien.

\section{PEMBAHASAN}

Diagnosa keperawatan merupakan keputusan klinis mengenai seseorang, keluarga, ataupun masyarakat sebagai akibat dari masalah kesehatan maupun proses kehidupan yang aktual atau potensial. Diagnosa keperawatan ialah dasar dari penyusunan rencana tindakan asuhan keperawatan. Diagnosis keperawatan sejalan dengan diagnosis medis dikarenakan dalam mengumpulkan data-data saat melakukan pengkajian keperawatan yang dibutuhkan agar menegakkan diagnosa keperawatan ditinjau dari keadaan penyakit dalam diagnosa medis.

Tujuan diagnosa keperawatan ialah untuk mengidentifikasi menurut Wahid \& Suprapto (2012) sebagai berikut : Masalah dimana adanya respon klien terhadap status kesehatan atau penyakit yang dialami. Faktor yang menunjang atau menyebabkan suatu masalah. Kemampuan klien untuk mencegah atau menyelesaikan masalah. Mengkomunikasikan masalah klien kepada tim kesehatan. Dan mendemonstrasikan tanggung jawab dalam indentifikasi masalah klien serta mengidentifikasi masalah utama untuk perkembangan intervensi keperawatan.

Diagnosis keperawatan sudah diterapkan di berbagai rumah sakit dan fasilitas kesehatan lainnya, namun pengetahuan perawat terkait indikator-indikator diagnostik untuk penegakan diagnosis keperawatan masih perlu ditingkatkan agar 
penegakan dapat dilakukan secara tepat dan sesuai dengan standar-standar yang telah ditentukan, serta proses penegakan diagnosis tidak dianggap sulit. Tanpa terminologi dan indikator yang yang sesuai dengan standar, penegakan diagnosis keperawatan menjadi tidak seragam, tidak akurat dan ambigu sehingga dapat menyebabkan ketidaktepatan pengambilan keputusan dan ketidaksesuaian asuhan keperawatan yang diberikan kepada klien.

Penegakan diagnosis dalam keperawatan memegang peranan penting dalam segala macam tuntutan masyarakat yang semakin kritis dan mempengaruhi kesadaran masyarakat akan hak-haknya dari suatu unit kesehatan. Pendokumentasian yang tidak dilakukan dengan lengkap bisa menurunkan mutu pelayanan keperawatan karena tidak dapat mengidentifikasi sejauh mana tingkat keberhasilan dari asuhan keperawatan yang telah diberikan dalam aspek legal perawat tidak mempunyai bukti tertulis jika klien menuntut ketidakpuasan akan pelayanan keperawatan (Nursalam, 2008; Iyer, 2001). Informasi yang menggambarkan suatu masalah klien atau diagnosis keperawatan kemudian mengarah kepada pemberian asuhan keperawatan untuk memilih suatu rencana perawatan yang sesuai dengan terapi keperawatan (Potter \& Perry; 2009).
Penegakan diagnosis keperawatan yang merupakan salah satu komponen standar asuhan keperawatan perlu dilaksanakan dengan baik sebagaimana yang diamanahkan dalam UU No.38 tahun 2014 tantang keperawatan yang terdapat pada pasal 30 bahwa dalam menjalankan tugas sebagai pemberi asuhan keperawatan, perawat berwenang menetapkan diagnosis keperawatan. Hal ini menegaskan wewenang perawat sebagai penegak diagnosis yang harus memiliki kemampuan diagnosis yang baik dan benar sebagai dasar mengembangkan rencana intervensi keperawatan dalam rangka mencapai peningkatan, pencegahan dan penyembuhan serta pemulihan kesehatan klien.

Diagnosa keperawatan ditegakkan berdasarkan dari respon fisik, sosiokultural, psikologis, dan spiritual klien terhadap masalah kesehatannya yang bersifat individual, sehingga diperlukan kemampuan berpikir kritis dalam proses diagnostik. Penegakkan diagnosa keperawatan haruslah didukung dengan sekelompok data dasar yang didapatkan oleh perawat saat melakukan pengkajian. Kelompok data ini disebut dengan batasan karakteristik. Batasan karakteristik merupakan indikator klinis yang merupakan dari tanda dan gejala objektif atau subjektif atau faktor risiko yang 
mendukung adanya kategori diagnostic . Indikator klinis yang akurat diperlukan untuk dapat memvalidasi diagnosa keperawatan yang ditegakkan. Keakuratan indikator klinis ditentukan dari kemunculan batasan karakteristik dan faktor yang berhubungan (etiologi) dari suatu diagnosa keperawatan.

Langkah - langkah menentukan diagnosa keperawatan menurut Setiadi (2012) adalah sebagai berikut:

1. Klasifikasi dan analisis data

Ialah mengelompokan data-data pasien atau keadaan tertentu dimana klien mengalami permasalahan kesehatan atau keperawatan berdasarkan kriteria permasalahan yang dialaminya. Klasifikasi ini berdasarkan pada kebutuhan dasar manusia yang dikelompokkan dalam data subjektif dan data objektif.

\section{Interpretasi data}

pertama, menentukan kelebihan dari pasien. Jika pasien memenuhi standar kriteria dari kesehatan, perawat akan menyimpulkan bahwa pasien memiliki kelebihan dalam hal tertentu dan kelebihan ini dapat digunakan untuk membantu menyelesaikan permasalahan yang dialami oleh pasien. Kedua, menentukan masalah pasien atau menyimpulkan pasien tidak memenuhi standar kriteria kesehatan maka pasien tersebut mengalami keterbatasan dalam aspek kesehatannya dan memerlukan pertolongan. Ketiga, menentukan masalah pasien yang pernah dialami olehnya, tahap ini perawat menentukan masalah potensial pasien. Keempat. Penentuan keputusan.

3. Memvalidasi diagnosa keperawatan. Merupakan menghubungkan dengan klasifikasi gejala dan tanda-tanda yang kemudian merujuk kepada kelengkapan dan ketepatan data. Untuk kelengkapan dan ketepatan data, kerja sama dengan klien sangatlah penting untuk dapat saling percaya, sehingga mendapatkan data yang tepat dan benar.

4. Merumuskan diagnosis keperawatan, dengan perumusan diagnosa yang tepat dengan kebutuhan pasien. Menyusun diagnosa keperawatan hendaknya diurutkan menurut kebutuhan yang berlandaskan hirarki Maslow (kecuali untuk kasus kegawat daruratan menggunakan prioritas berdasarkan “yang mengancam jiwa"). 
Pengkajian keperawatan dan perumusan diagnosa keperawatan mengawali langkah awal dari perencanaan proses keperawatan. Perencanaan ialah kategori dari perilaku keperawatan dimana dengan tujuan yang berpusat pada klien dan hasil yang diperkirakan ditetapkan dan intervensi keperawatan dipilih agar mencapai tujuan tersebut. Selama perencanaan, di buat secara prioritas. Selain berkolaborasi dengan klien dan keluarganya, perawat juga harus berkonsul dengan anggota tim perawatan kesehatan lainnya, menelaah dari literatur yang berkaitan, memodifikssi asuhan, serta mencatat informasi yang relevan tentang kebutuhan perawatan kesehatan klien serta penatalaksanaan klinik.

Diagnosis keperawatan dilakukan berdasarkan dari hasil pengkajian yang dilakukan oleh perawat sesuai dengan apa yang tertuang pada format pengkajian. Diagnosis keperawatan aktual adalah diagnosis keperawatan yang menjelaskan terkait dengan masalah nyata yang ada pada saat pengkajian dilakukan. Diagnosis keperawatan potensial ialah diagnosis keperawatan yang menjelaskan masalah nyata yang akan terjadi jika tindakan keperawatan tidak dilakukan. Jadi masalahnya belum ada tetapi penyebabnya sudah ada. Kekurangan dalam melakukan diagnosis keperawatan harus secepatnya dibenarkan dikarenakan akan menentukan dalam rencana tindakan sehingga pecapaian tujuan utama keperawatan dapat mengalami hambatan.

Diagnosis keperawatan berfungsi untuk dapat meningkatkan kualitas pengkajian yang dilakukan dan didokumentasikan oleh perawat. Diagnosis keperawatan sebagai proses yang terkait pada kajian deskripsi masalah pasien, penyebabnya, dan dapat memberikan informasi kepada perawat untuk mengidentifikasi pendekatan kajian apa yang sesuai untuk membuat perencanaan spesifik terkait diagnosis keperawatan pasien. Sehingga, secara tidak langsung akan membuat pengkajian perawat lebih komprehensif dan spesifik berorientasi pada masalah dan diagnosis pasien.

Kesalahan dalam menegakkan diagnosa keperawatan dapat mengakibatkan perawat salah dalam menentukan tujuan serta intervensi yang berdampak pada tidak teratasinya masalah yang di alami oleh pasien, meningkatnya masa perawatan serta biaya perawatan dan risiko terjadinya komplikasi. Oleh karena itu, ketika melakukan penelitian mengenai diagnosa keperawatan haruslah berfokus pada keakuratan indikator klinis. 


\section{PENUTUP}

Diagnosa keperawatan merupakan keputusan klinis mengenai seseorang, keluarga, ataupun masyarakat sebagai akibat dari masalah kesehatan maupun proses kehidupan yang aktual atau potensial. Diagnosa keperawatan ialah dasar dari penyusunan rencana tindakan asuhan keperawatan. Diagnosis keperawatan sejalan dengan diagnosis medis dikarenakan dalam mengumpulkan data-data saat melakukan pengkajian keperawatan yang dibutuhkan agar menegakkan diagnosa keperawatan ditinjau dari keadaan penyakit dalam diagnosa medis.

Diagnosis keperawatan berfungsi untuk dapat meningkatkan kualitas pengkajian yang dilakukan dan didokumentasikan oleh perawat. Diagnosis keperawatan sebagai proses yang terkait pada kajian deskripsi masalah pasien, penyebabnya, dan dapat memberikan informasi kepada perawat untuk mengidentifikasi pendekatan kajian apa yang sesuai untuk membuat perencanaan spesifik terkait diagnosis keperawatan pasien

\section{REFRENSI}

Apriyani, H. (2015). Identifikasi Diagnosis Keperawatan Pada Pasien Di Ruang Paru Sebuah Rumah Sakit.
Jurnal Keperawatan. 11(1):107-

111.

Cikwanto. Nupiyanti. (2018).

Pengembangan Instrumen

Penegakan Diagnosis Keperawatan

Pada Pasien Congestive Heart

Failure (Chf) Berbasis Standar

Diagnosis Keperawatan Indonesia

(SDKI). Jurnal Keperawatan 'Aisyiyah. 5(1):51-63.

Dewi, I.P. Dkk. (2020). Analisis Pengetahuan Perawat dalam Menentukan Diagnosis Asuhan Keperawatan Spiritual Islami di Rumah Sakit Syariah. Jurnal Ilmiah Keperawatan Indonesia. 4(1):73-87.

Ermayan. Dkk. (2017). Pengembangan

Format Dokumentasi Asuhan Keperawatan Berbasis Standardized Nursing Language (Snl) Nanda-I, Noc Dan Nic Di Ruang Rawat Inap. Mahakam Nursing Journal. Vol. 2(2): 50-61.

Rachmawati, U. Dkk. (2015). Tindakan Keperawatan Pada Klien, Keluarga dan Kader Kesehatan Jiwa dengan Diagnosa Keperawatan Isolasi Sosial di Komunitas. Jurnal Keperawatan Jiwa. 3(2):97-106.

Rofi'I, M. Dkk. (2018). Diagnosa Keperawatan Yang Sering Ditegakkan Perawat Pada Pasien Tuberkulosis Paru Di Rumah Sakit. 
Jurnal Kepemimpinan dan

Manajemen Keperawatan. 1(2):1-

8.

Santoso. R. Arief. (2018). Hubungan Pengetahuan dan Motivasi Perawat Dengan Kinerja Pendokumentasian Asuhan Keperawatan di Pelayanan Rawat Inap Puskesmas Guluk Guluk . Jurnal Ilmu Kesehatan. 3(1):10-19.

Sari, S.H. Dkk. (2015). Batasan Karakteristik Dan Faktor Yang Berhubungan (Etiologi) Diagnosa Keperawatan: Hambatan Mobilitas Fisik Pada Pasien Stroke. DK. 3(1):12-21.

Simamora, R. H., Bukit, E., Purba, J, M., \& Siahaan, J. (2017). Penguatan kinerja perawat dalam pemberian asuhan keperawatan melalui pelatihan ronde keperawatan di rumah sakit royal prima medan. Jurnal Pengabdian Kepada Masyarakat, 23(2), 300-304.

Simamora, R. H. (2019). Socialization of information Technology Utilization and Knowledge of information System Effectiveness at Hospital Nurses in Medan, North Sumatra. Editorial Preface From the Desk of Managing Editor ..., 10(9).
Srimiyati. Dkk. (2020). Aplikasi standar proses keperawatan: diagnosis, outcome, dan intervensi pada asuhan keperawatan. Jurnal Keperawatan Silampari. 3( 2):739-751.

Wulandini, P. Dkk. (2016). Faktor-Faktor Yang Berhubungan Dengan Pendokumentasian Asuhan Keperawatan Di Rumah Sakit Jiwa. Ners Jurnal Keperawatan. 12(2):131-142. 
